\section{Arquitectura como Construcción Estratificada}

ReBeCA BLANCo Rotea

Laboratorio de Arqueoloxía del Instituto de Estudios Gallegos Padre Sarmiento (CSIC-Xunta de Galicia)

\section{Resumen \\ El siguiente texto recoge los contenidos del póster presentado en el Seminario Internacional Arqueología de la Arquitectura celebrado en Vitoria en febrero de 2002. En él se presenta una línea de investigación desarrollada en el Laboratorio de Arqueología del Instituto de Estudios Gallegos Padre Sarmiento (CSIC-Xunta de Galicia) en Arqueología de la Arquitectura; concretamente se refiere, dentro de esta línea de investigación, a la aplicada en construcciones históricas.}

Palabras clave: Arqueología de la Arquitectura; Arqueología Aplicada; Análisis Estratigráfico; Arquitectura Rural; Arquitectura Eclesiástica.

\section{Abstract \\ This text goes over the content of the poster presented at the International Archaeology and Architecture Seminar held in Vitoria in February 2002. The work presents a line of investigation developed in the Laboratory of Archaeology of the Padre Sarmiento Institute for Galician Studies (CSIC-Xunta de Galicia) in Archaeology of Architecture. It makes specific reference within this line of investigation to research into historic constructions.}

Key words: Archaeology of Architecture; Applied Archaeology; Stratigraphic Analysis; Rural Architecture; Ecclesiastical Architecture.

\section{INTRODUCCIÓN}

Desde el año 1996 surge una preocupación en el seno del Laboratorio de Arqueología y Formas Culturales (IIT, USC) (en adelante LAFC) por que la comprensión, el conocimiento y la gestión del Patrimonio Construido gallego, se lleve a cabo desde una línea de investigación adscrita al campo de la Arqueología de la Arquitectura que presentase unos presupuestos teórico-metodológicos bien definidos. En este sentido se desarrolló una incipiente línea de trabajo que abordaba tanto las construcciones de época prehistórica, como protohistórica e histórica. En la actualidad esta misma línea de investigación se ha vinculado al recientemente formado Laboratorio de Arqueología del Instituto de Estudios Gallegos Padre Sarmiento (CSIC-Xunta de Galicia) (en adelante LAr), cuyos resultados se han presentado en el Seminario Internacional Arqueología de la Arquitectura a través de cuatro pósteres en los que se expone por un lado el programa general de análisis en patrimonio construido y por otro se ejemplifica con una serie de trabajos desarrollados en el seno de este laboratorio, que abordan desde la arquitectura funeraria de los túmulos megalíticos hasta el estudio de una pequeña iglesia parroquial situada en los Ancares lucenses. Este último caso, así como la metodología empleada, es el que se desarrollará en el presente texto.

Dicho programa de análisis parte, como se decía, de la premisa de que existe un Patrimonio Construido que debe ser gestionado. Así, desde el punto de vista de la investigación básica se pretende cubrir tres objetivos: facilitar la comprensión e interpretación del pasado; establecer una base teórica que observe la arquitectura como un producto social; y generar conocimiento. Por otro lado, desde una vertiente aplicada se atendería a la protección y gestión integral del Patrimonio.

A su vez, la metodología adoptada en dicho programa conlleva los siguientes objetivos: describir un espacio construido según su propia lógica sin introducir sentidos extraños a ella, es decir, deconstruirlo; y construir conocimiento arqueológico. Los presupuestos serían los siguientes: adoptar una aproximación tipo zoom integrando diferentes escalas que examinen regularidades espaciales en diferentes niveles; emplear el análisis formal como herramienta básica que implica la suma de deconstrucción y descripción; entender la arquitectura como un proceso constructivo; el modelo se concibe como la reconstrucción de su sentido original; mientras que el estilo como la forma regular de materialización de un concepto espacial, concepto que es constante para diferentes manifestaciones de la misma formación sociocultural; el último presupuesto establecería que el sentido espacial se puede interpretar mediante analogías débiles. 


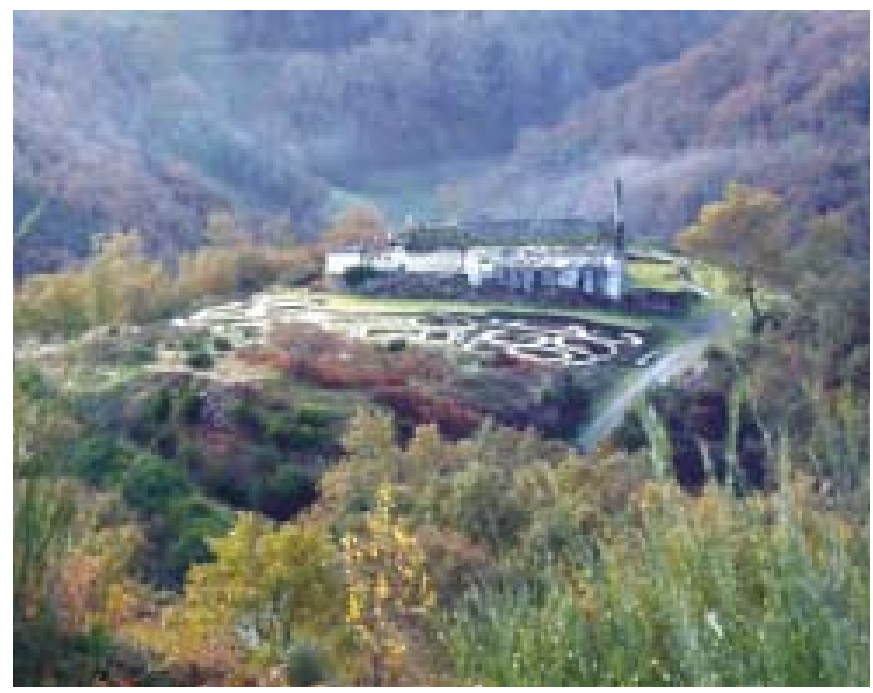

Fig. 1. Vista general del castro de Santa María de Castro (Cervantes, Lugo) y la iglesia parroquial emplazada sobre éste

Finalmente, las herramientas básicas adoptadas se basan por un lado en la deconstrucción y por otro en el uso de diagramas como elemento sintetizador. Así, dentro de esta línea se emplean el análisis formal, en el cual se englobarían el análisis estratigráfico (que desarrollaremos más adelante) y el análisis espacial, y los análisis de percepción, que a su vez engloban análisis de movilidad y análisis de condiciones de visualización.

\section{EL ANÁLISIS ESTRATIGRÁFICO DE ALZADOS COMO HERRAMIENTA METODOLÓGICA}

Como se ha indicado, ésta es una de las herramientas empleadas dentro de esta línea de trabajo y concretamente la que se ha aplicado en el estudio de la iglesia parroquial de Santa María de Castro. El objeto de estudio de este tipo de análisis es el espacio construido y se viene aplicando tanto a arquitectura protohistórica como histórica. Los objetivos que se pretenden cubrir con el empleo de esta metodología bajo los presupuestos de la Arqueología de la Arquitectura, son fundamentalmente cuatro:

-El estudio del espacio construido desde un punto de vista estructural, funcional y simbólico.

-Identificar, ordenar y datar las etapas de vida del edificio.

- Llevar a cabo el análisis pormenorizado de las unidades estratigráficas que conforman el edificio.

-Establecer su secuencia estratigráfica.

Esta metodología parte de modelos desarrollados con anterioridad en Historia del Arte, Historia de la Arquitectura y Arqueología. Básicamente se podría establecer su proceso de trabajo en los siguientes puntos (dicho proceso

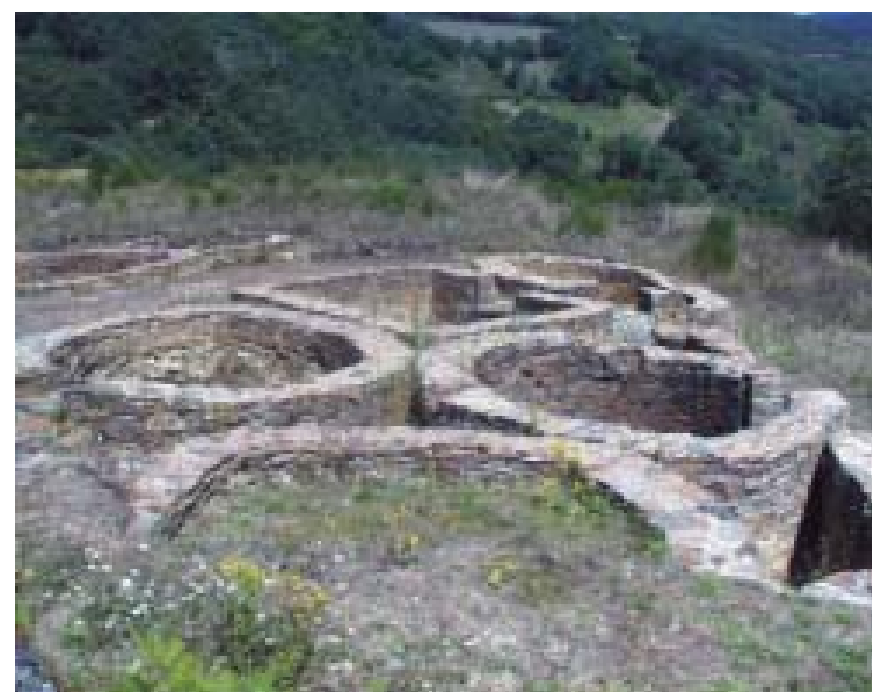

Fig. 2. Detalle de las cabañas circulares del Castro de Santa María de Cervantes

ha sido ya desarrollado y descrito por otros autores, CABALLERO, 1995: 37-46):

-Documentar gráficamente el espacio.

- Diferenciar, numerar y describir elementos.

- Lectura de relaciones temporales.

-Elaboración de diagramas.

-Reducción, periodización y correlación. Simplificación de elementos/identificación de actividades.

-Documentación histórica.

- Síntesis y datación.

-Archivo de datos/publicación.

Como se decía, dentro de esta línea de investigación se han desarrollado una serie de trabajos en arquitectura protohistórica e histórica cuya finalidad era, por un lado, poner en práctica los presupuestos anteriormente descritos que permitieran establecer unas bases teórico-metodológicas y, por otro, impulsar esta línea de investigación básica y aplicada en la comunidad gallega. Este fue el caso de Santa María de Castro (Cervantes, Lugo). Con anterioridad se habían efectuado tres campañas de excavación y consolidación en el castro y la necrópolis cristiana sobre los que se asienta la iglesia ${ }^{1}$. El presente texto se refiere fundamentalmente al análisis desarrollado en el edificio.

\footnotetext{
${ }^{1}$ Los datos referidos al Castro y necrópolis de Santa María de Cervantes se han extraído de los trabajos realizados por López González, Álvarez González y López Marcos (miembros de la Empresa Arqueológica Terra Arqueos S.L.) que se recogen en la bibliografía. Sus aportaciones han sido de gran ayuda para la elaboración del análisis de la iglesia y del presente trabajo.
} 
Fig. 3. Planta del sector excavado en las intervenciones arqueológicas

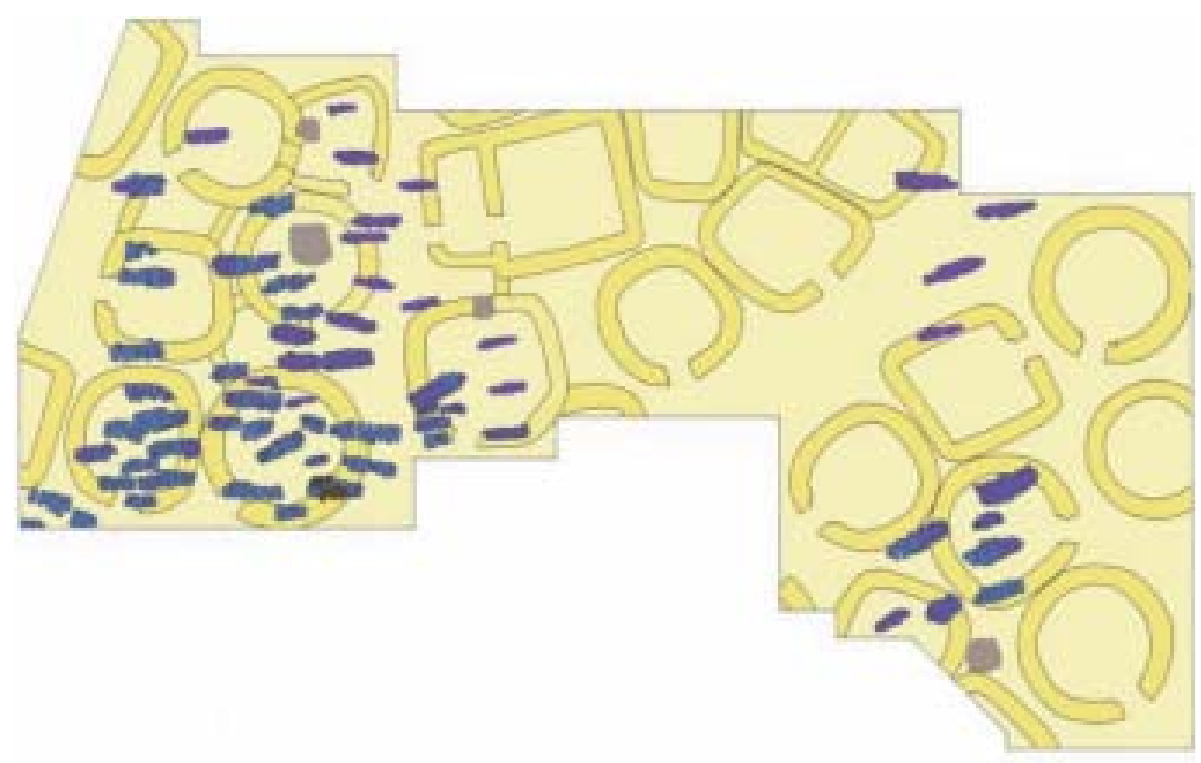

\section{LA IGLESIA PARROQUIAL DE SANTA MARÍA DE CASTRO $^{2}$}

\section{Antecedentes}

La iglesia de Santa María de Castro se localiza en el municipio de Cervantes (Lugo), en un pequeño valle de montaña situado en el W de la Sierra de los Ancares. Se asienta sobre un yacimiento castreño y una necrópolis cristiana. En el año 1994 durante las obras de remodelación del acceso a la iglesia de Santa María, quedan al descubierto una serie de estructuras que motivaron la realización de tres campañas de excavación en los años 1995, 1996 y 1999, a instancias de la Dirección Xeral de Patrimonio Cultural y ejecutadas por la empresa arqueológica Terra Arqueos. Estas intervenciones, que contemplaron excavación, consolidación y acondicionamiento de los restos, documentaron la existencia de un castro posteriormente ocupado por una necrópolis cristiana de época posiblemente bajomedieval.

A la hora de abordar el estudio de la iglesia de Santa María de Castro, y con la intención de establecer un acercamiento a aspectos referidos a su localización geográfica y su etapa de formación, eran básicos los datos facilitados por la excavación del castro y la necrópolis. En este sentido, la

\footnotetext{
2 A este trabajo han contribuido: Pilar Prieto Martínez (LAr, elaboración de dibujos de campo iniciales), César Parcero Oubiña, Eloi Saavedra Vidán (miembros del LAr, toma de datos topográficos en campo), Alicia Padín Otero (antiguo miembro del LAFC, sistematización de datos) y especialmente Cristina Brión Calo (colaboradora del LAr, equipo técnico en todo el proceso de trabajo). Finalmente, agradecer también a Anxo Rodríguez Paz (LAr) su contribución y asesoramiento en la elaboración de la parte gráfica.
}
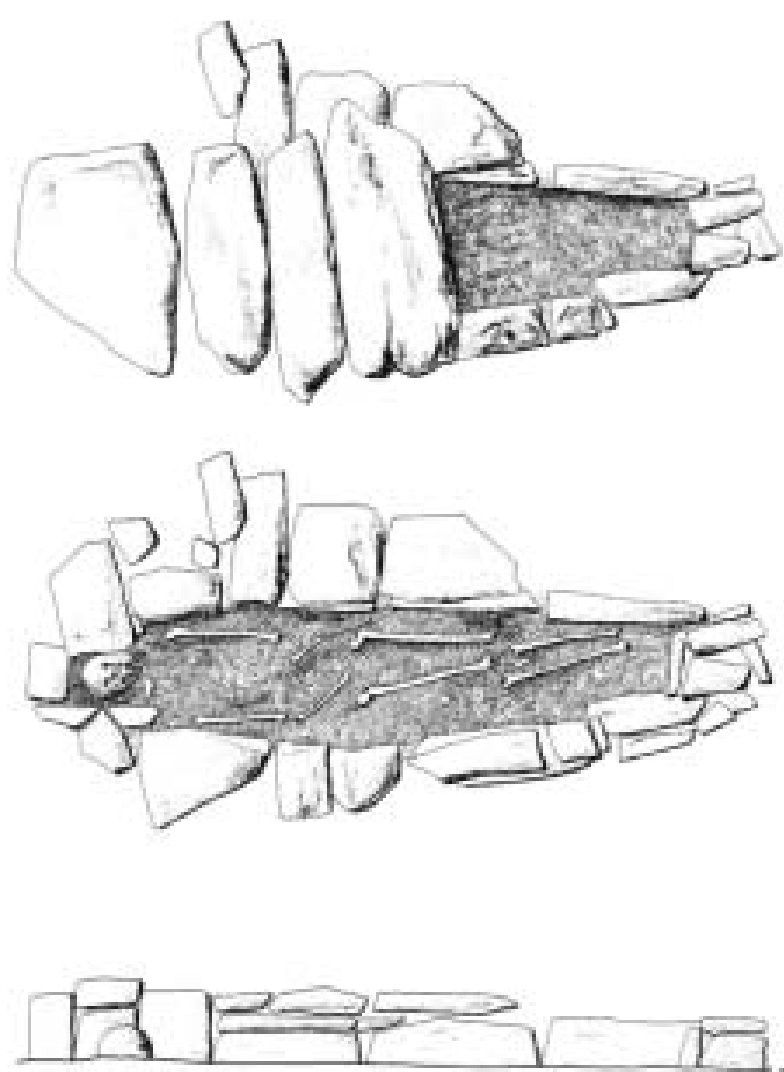

Fig. 4. Detalle de una de las sepulturas exhumadas 


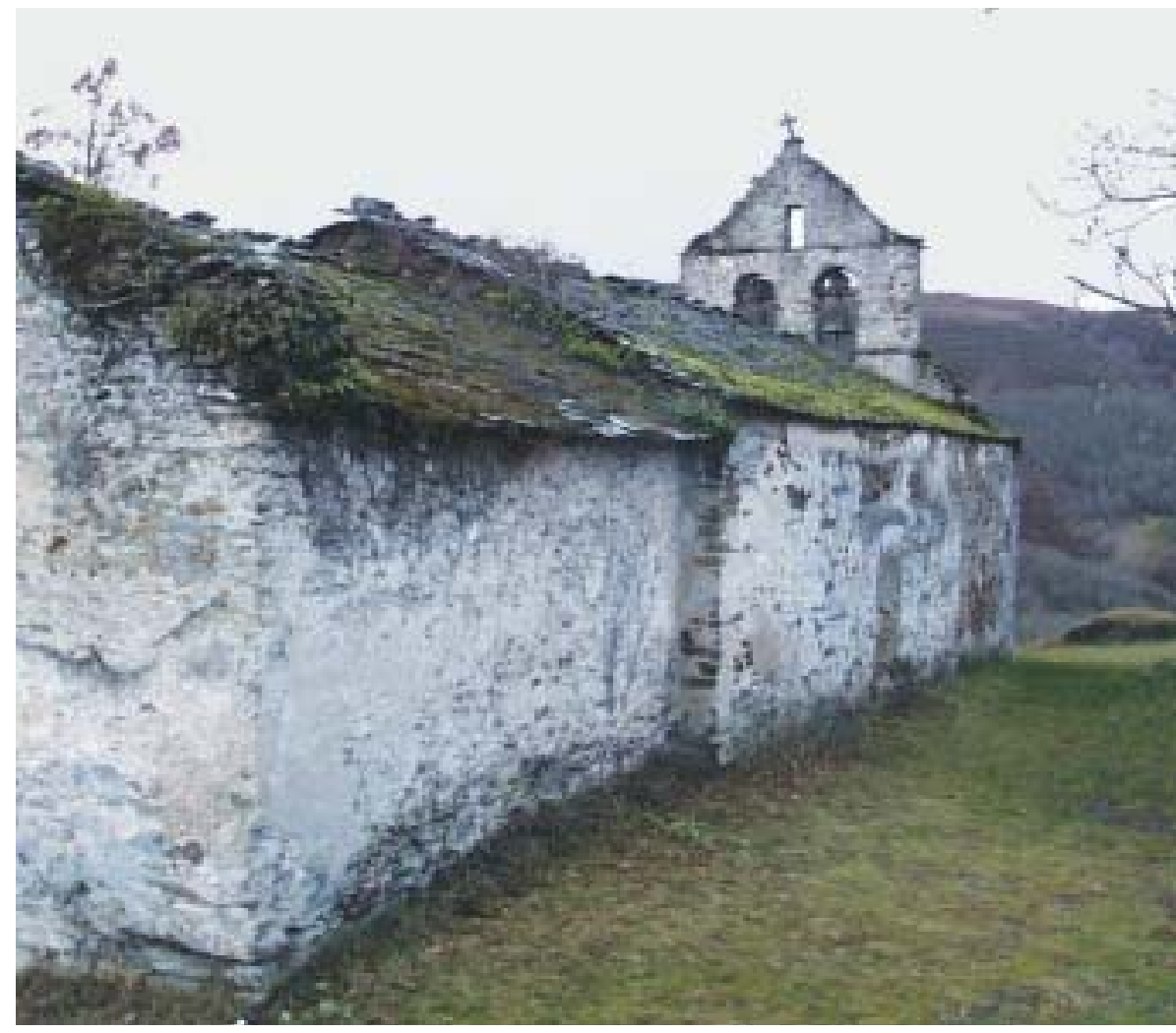

Fig. 5. Vista general del alzado $\mathrm{N}$ de la Iglesia de Santa María de Castro primera aproximación que se realizó al análisis de la iglesia se hizo a través de la comprensión de las ocupaciones existentes con anterioridad a la misma, el castro y la necrópolis, ya que podían proporcionar datos de gran interés a su estudio.

La iglesia parroquial había sido catalogada recientemente como contemporánea (s. XX), sin embargo eran varios los datos que apuntaban a que podría enclavarse en una cronología anterior, concretamente la existencia de unas pinturas murales (descubiertas durante las intervenciones arqueológicas) en una pequeña ventana situada en el testero, en la actualidad cegada tapando en parte las pinturas, y por la forma de la ventana alancetada, que hacían pensar que esa cronología podría ser errónea.

Estos datos llevaron a plantear la necesidad de realizar un estudio exhaustivo desde una metodología distinta, ya que la ausencia de elementos estilísticos o tipológicos o el tipo de técnica constructiva empleada imposibilitaban fechar correctamente el edificio desde planteamientos más clasicistas propios de otras disciplinas.

\section{Descripción}

Santa María de Castro es una pequeña iglesia rural de planta basilical absidiada. Se compone de nave única de planta rectangular y ábside de menor altura que la nave, también de planta rectangular. Debe indicarse que tanto la nave como el ábside no guardan proporciones regulares. La iglesia cuenta en la actualidad con dos vanos de entrada, situados en sus fachadas $S_{y} \mathrm{~W}$, ambos rematados al exterior por arcos de medio punto dovelados, con derrame al interior, el $\mathrm{S}$ adintelado y el $\mathrm{W}$ rematado en arco escarzano. Asimismo, se conservan cinco ventanas en su fachada meridional, todas ellas irregulares, con doble derrame y rectangulares al exterior e interior, exceptuando la más occidental abierta en el ábside que es de medio punto al interior. En el testero se conserva también una pequeña ventana de forma alancetada.

Toda la fábrica está realizada en aparejo de mampostería de lajas de esquisto, posiblemente revestida en su totalidad al exterior, conservándose el revestimiento en algunas zonas. Se debe indicar que el edificio carece de elementos de estilo, con excepción de la ventana alancetada anteriormente citada y una espadaña de tres cuerpos que corona su fachada W.

\section{SÍNTESIS DE LOS RESULTADOS OBTENIDOS DEL ANÁLISIS DE SANTA MARÍA DE CASTRO}

\subsection{Resultados del análisis documental e histórico- artístico}

Se han revisado fuentes documentales directas e indirectas, de las cuales se pueden extraer algunos datos interesantes: 
- Su catalogación es confusa, ya que unos autores la adscriben a época moderna y otros a época contemporánea (s. Xx) de estilo Historicismo clasicista.

- La referencia documental más antigua es del año 1584, momento en que se denomina al edificio como $c a-$ pilla.

- Las fuentes escritas posteriores a este año no ofrecen datos de interés, tan sólo una referencia cronológica a su existencia. Algunos de ellos, ya en el s. XX nos hablan de reparaciones puntuales.

- La escasez de referencias al edificio dificultaba en estudios anteriores su asignación a un estilo histórico o a una cronología absoluta.

A modo de conclusiones se puede indicar lo siguiente:

-Responde a la tipología de iglesia rural habitual en la zona de montaña lucense. Presenta peculiaridades propias:

- Mampostería de piedra local

- Pórtico o cabildo antepuesto a la fachada

- Muros gruesos y escasa altura de las naves

- Escasos vanos y de pequeño tamaño

- Fachada de corte pentagonal rematada en una espadaña habitual en el barroco rural gallego entre el $2 .^{\circ}$ $1 / 3$ del s. XVIII y 1/2 del s. XIX. En esta zona se realizan en lajas de pizarra motivando la ausencia de elementos decorativos.

- La planta es un modelo que se repite en el arte rural gallego desde la Edad Media hasta la Edad Moderna.
- Sus elementos estructurales y aspectos técnicos se ajustan al tipo de templo rural gallego común entre el s. XVI y el s. XIX.

\subsection{Resultados del análisis estratigráfico}

La pervivencia de tipologías y técnicas constructivas en el arte rural gallego, el uso de piedra local y la ausencia de elementos de estilo, dificultaron en gran medida la lectura. Sin embargo, el rigor de esta metodología permitió llevar a cabo un análisis exhaustivo en el edificio y se cree que precisamente en estos casos, donde no se trabaja con arquitectura monumental, este tipo de estudios permiten identificar la secuencia del edificio, que de otra forma quedaría incompleta.

\section{Fase bajomedieval: finales del S.XIII - S.XIV}

En las zonas bajas del ábside y parte del segundo tramo de la nave se identificaron restos de una fábrica con un aparejo diferente al conservado en el resto de la iglesia (mampuestos de mayor tamaño dispuestos en hiladas bastante regulares) y a diferencia de éste asentado a hueso. Se trataría de los restos de una planta anterior sobre la que se construye la iglesia actual, contemporánea a la necrópolis excavada de finales del s. XIII - s. XIV, datada en esta fecha gracias a la aparición de una moneda de esta época documentada durante las excavaciones y al tipo de tumbas exhumadas en la necrópolis. Se considera que este primer edificio, de menores dimensiones que el actual y concebido como capilla, tendría relación con los procesos de cristianización del castro.

Fig. 6. Distintas fases del proceso de trabajo: toma de datos en campo, elaboración de la planimetría e introducción de datos en un archivo informático

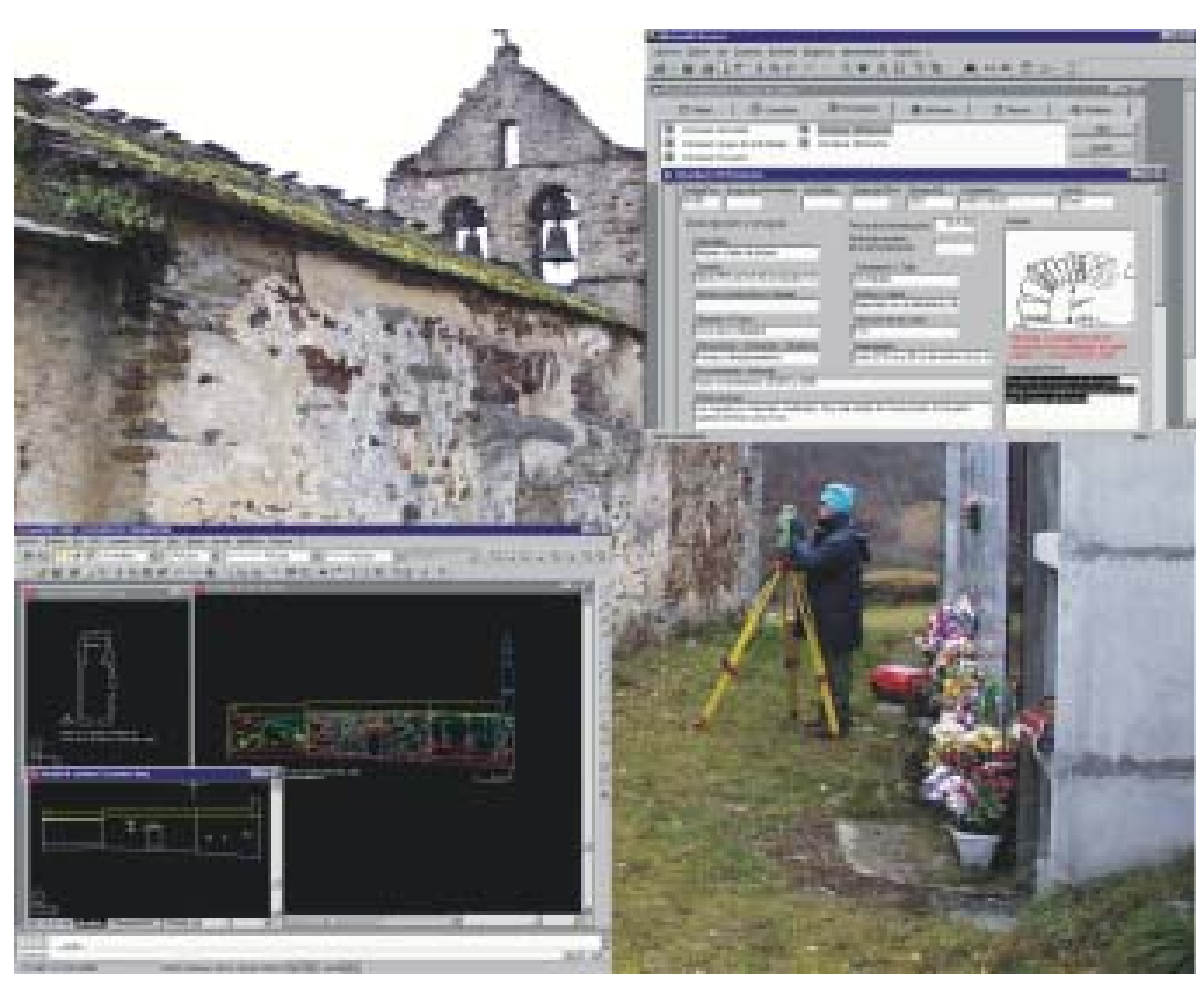




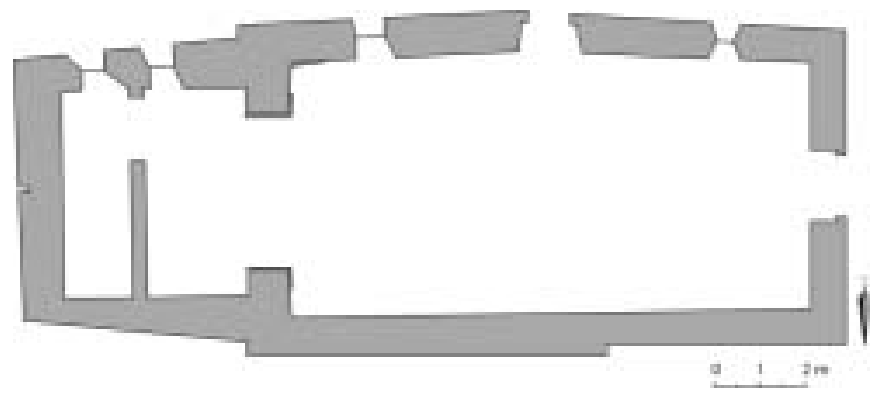

Fig. 7. Planta de la iglesia parroquial de Santa María de Castro (Cervantes, Lugo)

\section{Fase tardogótica: finales del s.XV}

Sobre esta fábrica, se levanta una nueva iglesia, posiblemente con la misma planta, a finales del s. XV. De este período se conservan el ábside y parte de lo que constituye hoy el segundo tramo de la nave, ambas estructuras estaban realizadas en aparejo de mampostería de lajas de pizarra de pequeño tamaño, tendiendo a formar hiladas y presentaba restos de un mortero de cal (aunque se han recogido muestras de los morteros, revestimientos y pinturas, todavía no se han obtenido los datos resultantes de los análisis). Conservamos como fósil director la ventana alancetada del ábside, en cuyo interior se conservan unas pinturas fechadas en el s. XVI. Es el análisis formal de esta ventana, el que nos lleva a datar esta fase en un momento tardogótico, en el que aún se están empleando tipos que en otras zonas ya se han sustituido por nuevas formas más propias ya de época moderna.

\section{Fase moderna I: último tercio del s.XVI}

En el último tercio del s. XVI se produce una ampliación de la nave tardogótica hacia el W, que respondería a la conversión del edificio en iglesia parroquial, ya que aunque existe una importante ausencia documental entre fin. del s. XVI y fin. del s. XVII período en el que pasa de denominarse capilla a iglesia parroquial en los documentos conservados de ambas fechas. Como consecuencia podría derivarse la necesidad de ampliar el edificio para dar cabida a un mayor número de fieles con motivo de la nueva situación del edificio. A este período correspondería también la construcción de la puerta $\mathrm{N}$ del edificio y las pinturas que cubrirían al menos el ábside, de las cuales se conservan restos visibles en el interior de la ventana del testero, aunque se cree que podrían conservarse también en el ábside, actualmente encalado, a no ser que hayan sido afectadas por un incendio que se ha documentado en el s. XX por fuentes orales y que motiva la reforma del mismo.

Por otro lado, se ha observado la existencia de restos de estucado en el exterior del ábside y en diferentes partes del segundo tramo de la nave. Se han fechado estos restos en esta misma fase, ya que se considera que corresponderían a la misma función que las pinturas del ábside, un embellecimiento interior y exterior del edificio relacionado con la nueva entidad del edificio como iglesia parroquial.

\section{Fase moderna II: finales del s. XVII}

En época barroca se produce una nueva ampliación de la nave de la iglesia hacia el W, que coincide con un aumento poblacional en la zona. Se ha identificado en esta fase un cambio de aparejo con respecto a las anteriores, aunque se trata también de un aparejo de mampostería de pizarra, ahora se emplean bloques de mayor tamaño y el aparejo es irregular, sobre todo en las zonas más altas del edificio. Posiblemente por las características del terreno, el edificio está situado sobre un espolón concretamente sobre la acrópolis del castro, esta ampliación es de menores dimensiones en anchura que el segundo tramo de la nave (el más oriental), empleando en los alzados $\mathrm{N}$ y $\mathrm{S}$ distintas soluciones, en el $\mathrm{N}$ se resuelve mediante un retranqueo mientras que en el $\mathrm{S}$ se produce un ligero giro de la planta hacia el N. Se desconoce cómo sería el cierre de esta ampliación por el W, ya que la fachada que presenta en la actualidad la construcción correspondería a la fase siguiente.

\section{Fase moderna III: finales del s. XVIII - principios del S.XIX}

En este momento se lleva a cabo el cierre del edificio por el W mediante una fachada de corte pentagonal rematada en una espadaña de dos cuerpos a la que se accedería mediante una escalera lateral por el lado $S$, a la que se adosa un pórtico o cabildo. En la actualidad se ha perdido el cabildo, pero se conservan en otras iglesias de la zona. Estas estructuras funcionaban como pórticos para resguardo de los feligreses, pero también, y de ahí su denominación, como lugares donde el cabildo llevaba a cabo tareas administrativas en relación con la parroquia. También se ha perdido la escalera de acceso a la espadaña.

Ambas pérdidas se producen cuando a prin. - 1/2 del s. XX el párroco lleva a cabo obras en el entorno de la iglesia para crear un acceso directo desde el W mediante una escalera, lo cual obliga a eliminar la estructura que forma el cabildo y a su vez las escaleras que se apoyaban en éste.

Asimismo corresponderían a esta fase la apertura de ventanas rectangulares con doble derrame en el alzado $S$, la apertura de la puerta $S$, de las mismas características que la W. También se cierran los vanos del alzado N, la puerta del XVI y una pequeña saetera posiblemente del edificio de finales del s. XV. Finalmente, se lleva a cabo el revestimiento exterior de todo el edificio. 


\section{Fase contemporánea I: s. XIX}

En esta fase las obras llevadas a cabo no afectan a la estructura del edificio. A lo largo del s. XIX se producen roturas importantes en los muros, motivadas en parte por las reformas llevadas a cabo en la fase anterior. Éstas afectan fundamentalmente al alzado $S$ del edificio, debajo de las ventanas, y al ábside. Se llevan a cabo las reparaciones de estas roturas, así como un nuevo revestimiento del exterior de la construcción.

\section{Fase contemporánea II: s. XX}

Ya en el s. XX se cubre nuevamente el edificio, con una cubierta a dos aguas realizada en lajas de pizarra, como se ha documentado gracias a los libros de fábrica conservados de este siglo. También se llevan a cabo reformas en el interior del templo, en el artesonado que se soluciona ahora con un entablado de láminas de madera, en el ábside y se reviste todo el interior. Asimismo se elimina el cabildo y la escalera de acceso a la espadaña. Finalmente, se llevan a cabo nuevos revestimientos puntuales en el exterior de la construcción.

\section{FINALIDAD DEL ANÁLISIS}

Como se veía al principio, el análisis efectuado en esta pequeña iglesia parroquial tenía una finalidad muy concreta, que a su vez conllevaba otras intenciones. Por una lado, se pretendía impulsar la línea de investigación anteriormente descrita, fundamentada en la Arqueología del Paisaje como marco teórico y la Arqueología de la Arquitectura como marco metodológico, y que en la actualidad, en Galicia, está todavía en sus fases iniciales. Por otro lado, y en este mismo sentido, se cree que es necesario establecer en nuestra comunidad pautas y criterios de actuación en Arqueología de la Arquitectura y concretamente en el análisis estratigráfico de alzados.

Además, ante la posibilidad, dado el estado de ruina en que se encuentra el edificio, de que se efectúe un proyecto de restauración del mismo, se cree que podía contribuirse al proyecto con los resultados obtenidos del análisis. En relación con este punto, deberían tenerse en cuenta los siguientes aspectos:

- La información generada de la presente investigación.

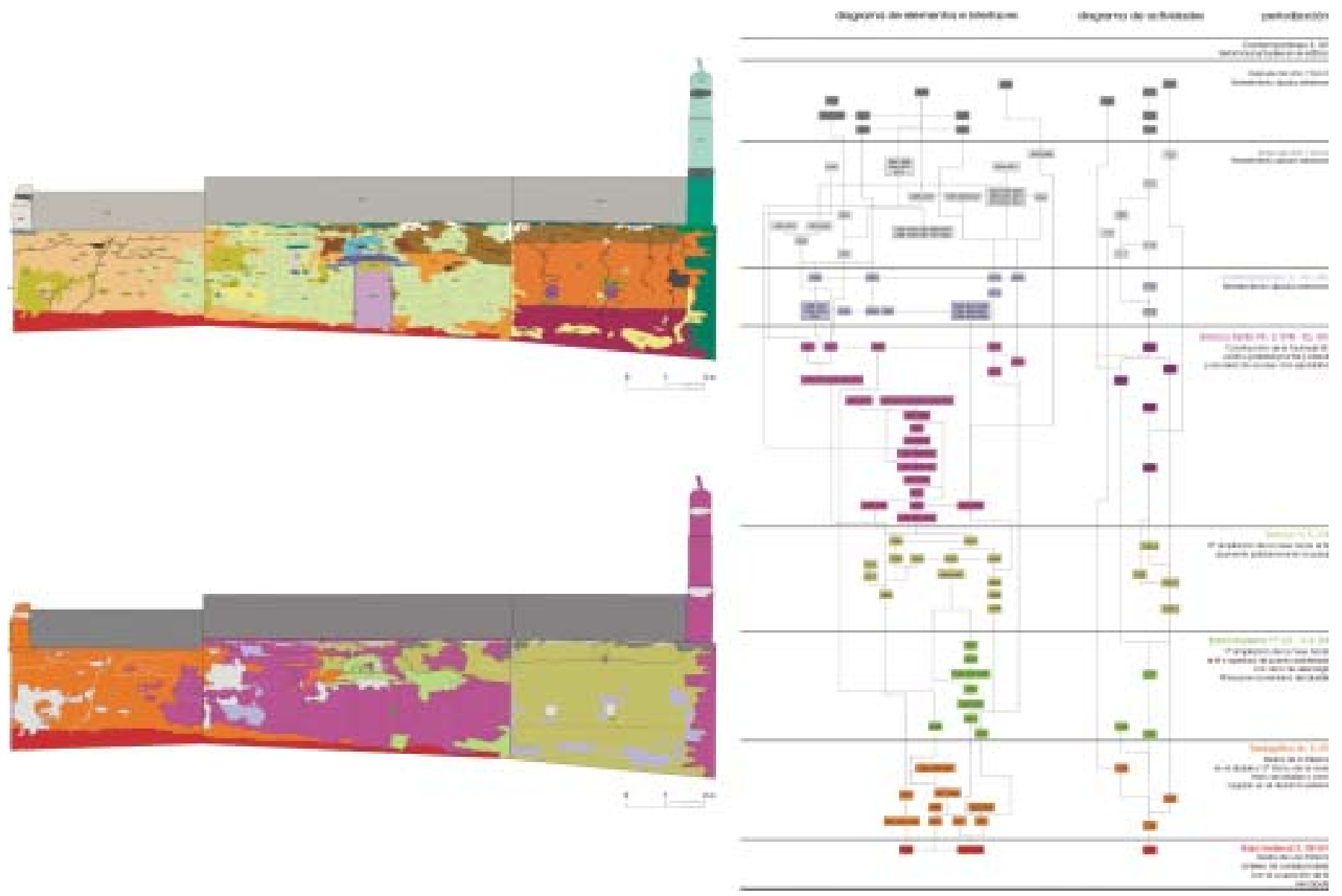

Fig. 8. Alzado N con la diferenciación de elementos y actividades y diagramas de elementos y actividades con su periodización 
- La necesidad de efectuar una nueva lectura una vez levantados los revestimientos en el interior del edificio donde no se pudo efectuar un análisis completo debido a que no se observaban sus fábricas, ya que se cree que podrían conservarse pinturas al menos en el ábside, en relación con las pinturas documentadas en el abocinamiento de la ventana absidial.

—La necesidad de realizar una excavación en área en el interior del edificio y parte de su exterior, que permita conectar estratigráficamente castro, necrópolis cristiana y primitiva capilla.

Finalmente, se pretendía contribuir al interés demostrado por la empresa arriba mencionada por que se efectuase un estudio completo del edificio que permitiese establecer una conexión entre la iglesia y el yacimiento excavado, en caso de existir. Su intención era la de conseguir que el estudio fuera contemplado en el proyecto de restauración y continuar con los trabajos en el castro, que implicaran su revalorización, dada la potencialidad del yacimiento.

\section{Bibliografía}

BALSA DE LA VEGA R., 1912, Catálogo-Inventario monumental y artístico de la Provincia de Lugo: lo llevó a término por Real Orden de 21 de junio de 1911.

CABAllero Zoreda L., Método para el análisis estratigráfico de construcciones históricas o "lectura de paramentos», Informes de la Construcción, 453, pp. 37-46.

FERNÁNDEZ GÓMEZ R. M. ${ }^{\text {a }}$ 1998, El Arte Religioso en la Sierra Oriental de la provincia de Lugo, por tierras del Camino Primitivo (s. XV-XX). Catalogación, tesis doctoral (editada en CD).

García Conde A. Y López Valcárcel A., 1999, Epistológico Lucense, Lugo: Fundación Caixa Galicia.

García Iglesias J. M., 1979, La pintura en Galicia durante la Edad Moderna: el siglo XVI, Santiago.
García Iglesias J. M., 1986, La Pintura Manierista En Galicia, La Coruña.

GarCía Iglesias J. M., 1989a, Pinturas inéditas en Galicia del s. XVI, Cuadernos de Estudios Gallegos, XXXVIII, n. ${ }^{\circ} 103$.

García Iglesias J. M., 1989b, Pinturas murais de Galicia, Santiago de Compostela.

LÓpez GonZÁlez L. F., ÁlVAREZ GonZÁlez Y., 2000, El poblado minero de Sta. María de Castro (Cervantes, Lugo), III Congresso de Arqueologia Peninsular, Volume V, Proto-História da Península Ibérica (Porto, ADECAP, 2000).

López GonZÁlez L. F., Álvarez GonZález Y., López Marcos M.A., 1996, Informe preliminar da segunda campaña de escavación, consolidación e acondicionamento do Castro de Santa María de Castro (Cervantes, Lugo), (Informe inédito depositado en la Dirección Xeral de Patrimonio Cultural en 1996).

LÓpez GonZÁlez L. F., Álvarez GonZÁlez Y., LÓpez Marcos M.A., 1999. Informe valorativo da actuación arqueolóxica no Castro de Santa María (Cervantes, Lugo), (Informe inédito depositado en la Dirección Xeral de Patrimonio Cultural en 1999).

López Valcárcel A, 1996, Guía de la Diócesis de Lugo, Suplemento del Boletín Oficial del Obispado de Lugo, Lugo.

López VALCÁrCel A., 1991, Las visitas pastorales del Obispo D. Lucas Bustos a la Diócesis de Lugo, Memoria Eclesiae, XV, HeVIA Ballina A. (Ed.), 1997, Las visitas pastorales en el ministerio del obispo y archivos de Galicia: santoral hispano-mozárabe en las diócesis de España, Madrid, Actas del XIII Congreso de la Asociación de Archiveros de la Iglesia en España (Sevilla 11 al 16 de septiembre de 1997).

VAliÑa SAMPEDRO E., 1975-1983, Inventario artístico de Lugo y su provincia, (V. II. 1975), Madrid.

Valiña Sampedro E., 1991, Catálogo de los Archivos parroquiales de la Diócesis de Lugo, Lugo.

VÁZQUEZ R. M. ${ }^{a}, 2000$, La actividad artística en el Camino Francés de las peregrinaciones en la provincia de Lugo entre 1500-1800, tesis doctoral, (edición en CD).

Vila Jato M. ${ }^{a}$ D., García Iglesias J. M., 1993, Galicia en la época del Renacimiento, en Rodríguez Iglesias F. (Dir.), 1993, Galicia Arte, XII, A Coruña.

Vv.AA., 1915, Guia Eclesiástica de la Diócesis de Lugo, Lugo.

Vv.AA., 1941-1978, Boletín de la Comisión Provincial de Monumentos Históricos y Artísticos de Lugo, Tomos: I, II, V (3 vol.), VI (1954-5), VI (1956-7), VII (1963), VII (1964), VIII (1969-70), IX (1974-5), Lugo. 